\title{
APPRECIATIVE EDUCATION TO ENHANCE QUALITY OUTPUTS THROUGH ASSESSMENT AND FEEDBACK PRACTICES
}

\author{
Dr Isabel Coetzee \& Dr Tanya Heyns
}

University of Pretoria

\begin{abstract}
Higher education is experiencing a time of change that is rife with challenges. The times call for educators in the nursing profession to facilitate learning in a way that students are empowered to become future leaders in the profession. Appreciative inquiry is an emerging educational method that is used to bring about organisational transformation in the teaching and learning arena. It is an approach to learning where emphasis is laid on positive aspects about learning rather than negative aspects.
\end{abstract}

The purpose of this article is to explain how appreciative education is implemented in nursing education institutions including the assessment and feedback practices to enhance outputs.

Key words: appreciative education, appreciative inquiry, assessment, feedback

\section{Introduction}

\author{
"Imagine a nursing education institution where nurse educators and students are \\ valued, supported and empowered to strive towards educational excellence."
}

-Farrugia and Rietdyk-

The above words of Farrugia and Rietdyk (2004) in Rietdyk (2005) envision a nursing education institution (NEI) where an ideal environment is created in which educators and students can flourish; thus, an NEI environment where students are "valued, supported and empowered".

Higher education is experiencing a time of tremendous change that is rife with challenges, but also with opportunities. It is therefore imperative that educators in the nursing profession facilitate learning in a way that students are empowered and emboldened to become future leaders in the profession and become professional nurses who enter the profession with new ideas, innovations and as self-directed learners with higher skills and competency levels that can only augment and extend the essential role they play in the running of health services. 
Educators should foster creativity and innovation in nursing education through processes that focus on co-constructing the future of students, NEIs, and the communities served. To achieve quality education and training and higher competency levels, educators are obliged to use continuous assessment and feedback in order to facilitate learning and ensure quality outputs. Assessment and grading practices have the potential, not only to measure and report learning, but also to promote learning. Grading should not be designed to make comparative judgements among students; rather, it should focus on each student's abilities, strengths and learning needs to enhance individual learning by providing constructive feedback (Earl 2003). The preferred future of assessment is "one that makes assessment [and feedback] an integral part of learning — guiding the process and stimulating further learning" (Earl, 2003).

Through assessment and feedback practices, educators can deliver quality nurse practitioners who promote the collective destiny (vision) set by the National Department of Health (2007) which is to assure quality in healthcare and to continuously improve healthcare delivery to all citizens. This involves measuring the gap between the set standards of the National Department of Health and the actual practice (through assessment and feedback), and then working out ways to close the gap and move towards quality education and training.

Armstrong (2008) states that 'quality' has become a buzzword in today's society. Politicians assure communities that the healthcare services will provide quality healthcare to them. Healthcare organisations guarantee a quality experience for patients and significant others (families) if the services they provide are used. Educators, on the other hand, strive to produce 'quality products' in terms of delivering competent and socially prepared nurse practitioners (Armstrong 2008). Educators, students and clinical facilitators therefore need to determine a collective destiny for each programme offered at the NEIs. Educators should measure the outcomes through assessment and promote quality through feedback; they should plan and implement actions to refine programmes so as to enhance the knowledge, skills and academic outcomes of students.

Assessment and feedback is stressful and can be perceived as negative if the educators tend to focus on 'what is wrong'. As an alternative, educators can use an Appreciative Inquiry approach during assessment and feedback practices. The focus of this article is to illustrate such an approach towards assessment and feedback practices that can be used in programmes, modules and clinical practice to promote quality products and healthcare.

\section{Appreciative Inquiry}

Appreciative Inquiry (AI) is a collaborative approach towards positive institutional (educational) changes. Appreciative Inquiry is a philosophy, a model of change, and a set of tools and techniques 
that supports the discovery, dreaming, design and creation of a shared vision that inspires people in an organisation to move towards a collective destiny (Stefaniak 2007). Appreciative Inquiry is a "coconstructed practice informed by all those who work on creating the conditions for growth and change based upon seeking the positive core" (Stefaniak 2007). In higher education, the positive core is found wherever people are working in ways that enhance learning as well as the mission and purpose of higher education. The positive core can be the basis for what the institution might do next. For educators, the positive core can be to strive towards educational excellence, which implies quality education and training of students, satisfactory academic outcomes and delivering to the profession quality students with high skills. As educators we need to rethink our approach in order to transform educational practices and bring about positive change.

Appreciative Inquiry is an emerging method that is used to bring about organisational transformation. It looks at issues, concerns and challenges in a different (positive) way (Coghlan, Preskill \& Catsambas 2003). When people focus on human ideals and achievements, peak experiences and best practices rather than on problems, challenges and conflicts, they tend to flourish (Mohr \& Watkins 2002). Discovering and supporting educators' and also students' passions, skills, knowledge, experiences and successes will excite them and mobilise them to implement innovations (Mohr \& Watkins 2002).

In the facilitation of learning, the foundation of AI stresses that learning from moments of joy (peak experiences), from wonders and excellence, creates an invigorating environment wherein NEIs and all stakeholders (educators, students and preceptors) can flourish. This is a radical departure from previous methodologies that centred on 'what is wrong'. For example, when applying the AI approach, the educator asks students at the end of a session, study theme, module, clinical accompaniment session or practical session questions such as: "What did you enjoy the most about today's activity?"; "What was your peak experience?”; "What was the best about ...?" Such positive questions give students the opportunity to reflect on the learning experience and highlight the positive aspects that enhance the learning experience for them. To give positive feedback about their day's learning experience stimulates the students' internal motivation to learn more. The implication for the educator is to have direct feedback from students on what worked well and what they want more of in relation to the learning opportunity provided to them.

Appreciative Inquiry highlights 'what is going right' and attempts to purposefully move the organisation in that direction, reflecting the belief that the greatest potential for improvement comes from embracing what works well in an organisational setting. The AI approach has been introduced as a method to design change, manage conflict and build team strategies for a variety of organisations (Erp \& Lovrich 2006; Havens, Wood \& Leeman 2006). Appreciative Inquiry and collaborative forms of evaluation practices emphasise social constructivism, where positive/appreciative questions are 
asked to promote dialogue and interaction with educators, students and/or clinical facilitators and are used to give meaning and make sense of current educational practices. Furthermore, both appreciative inquiry and learning-oriented forms of evaluation view inquiry as ongoing and iterative and as a process that should be integrated into everyday assessment of educational practices. Findings (feedback/inputs) should be used for decision-making and taking of action to enhance educational practice, as suggested by Coghlan, Preskill \& Catsambas (2003).

The power of AI lies in the way in which students become engaged and inspired by focusing on their own positive experiences. It is the view of Reed (2007) that AI concentrates on exploring ideas that people have about what is valuable in what they do, and then tries to work out ways in which this activity can be strengthened. The emphasis is firmly on appreciating the tasks and responses of people (students), rather than concentrating on their problems. The radical aspect of AI is in the way that it challenges people to rethink their ideas on how people work, how changes happen, and how research can contribute to this process.

This approach to personal and organisational change is based on the assumption that questions and dialogue about strengths, successes, wishes, hopes and dreams are in themselves transformational. It is founded on the belief that people, individually and collectively, have unique gifts, skills and contributions and that the organisations in which they work are human social systems where, through inquiry and dialogue, people can shift their attention and action away from problem analyses to identifying worthy ideals and possibilities for the future (Moore 2008). Hence, AI refers both to a search for knowledge and a theory of intentional collective actions which are desired to help develop the collective vision that will help a group, organisation or society as a whole (Cooperrider \& Srivastva 1987; Watkins \& Cooperrider 2008).

\section{The nature of questions asked in appreciative inquiry}

Asking students what their wishes are for a specific activity, study theme, module, clinical accompaniment session and/or practical session gives them the opportunity to reflect on the "negative aspects', but in a positive (AI) way. For example, students may wish to have more clinical accompaniment sessions because they have learned so much during these sessions. This then implies to the educator that there is a need to increase the number of such sessions because it was indicated by the students that they learn a lot during this process.

Suggestions of appreciative questions that will generate forward movement are:

- "Think about a time that you as a student were performing at your best, and you felt engaged and valued. Tell me a story about that time." 
- "What were you and the other students doing that excited/interested/stimulated you?"

- "What are your wishes for future students regarding this activity, study theme, module or programme, etc.?"

Educators need to analyse the wishes as reflected by students, because it enables educators to identify areas/aspects of the learning opportunity, study theme, module or programme that need to be refined. Students can reflect verbally (usually a more informal assessment) or in writing (more formal assessment) on a specific learning opportunity, study theme, module or programme. For example, after the educator has accompanied students on a clinical ward round, she or he can ask each student in the group: "What was your peak/best learning experience during today's ward round?" and "What are your wishes for future ward rounds?"

Listening to the students' feedback allows the educator to gain insight into what the students' peak learning experiences were. Paying attention to the learning experiences specifically mentioned and the aspect(s) they want (desire) will increase the value of the ward round. It will further indicate what aspect can be improved on or enhanced during the next ward round as a learning opportunity. For example, if most of the students reflect: "Ma'am [educator] I wish we could do a ward round every day" it translates to indirectly expressing a need to have more learning opportunities by means of ward rounds. The educator then has to reflect critically on the feedback received and identify how the learning opportunity can be adapted and refined. In the case of the mentioned example, the educator needs to reflect on and plan ways to provide more opportunities for students to participate in ward rounds as learning opportunities.

Traditionally, educators focus on the negative aspect of a learning activity, module or programme, as evidenced in the examples of questions usually asked below. However, considering the forward movement which is the core of the AI approach, such questions will not generate such movement.

- "What is wrong with the ...?"

- "Why are the students performing so poorly?"

- "What is causing conflict between students and preceptors and who is responsible?"

Being asked to answer questions conveyed in a negative manner may result in students experiencing feelings of failure and negativity that, in turn, have an adverse effect on innovation and creativity. These types of questions will not generate forward movement, and may cause demotivation and inability to plan for actions to improve academic performance and outcome.

\section{Appreciative education}


At organisational (NEI) level, it is important for the educator to design and implement an assessment and feedback system that ensures that these activities contribute to continuous learning and informed decision-making. It further warrants that the findings will be utilised to enhance the educational practices as stated by Preskill and Catsambas (2006).

A practical approach for educators on how to utilise appreciative education is to follow the six easy steps suggested by Bloom, Hutson, He and Konkle (2013) in their everyday educational practice. In Figure 1, a schematic presentation of the Six-D phases is illustrated.

The Six-D phases that can be used in everyday educational practice include:

- Disarm: Recognise the importance of first impressions, create a safe, welcoming authentic environment.

- Discover: Use positive open-ended questions to draw out what the students enjoy doing, their strengths and their passions. Listen carefully to the answers.

- Dream: Assist the students to formulate a vision of 'what I might become' in the study theme, module or programme and assist them in developing their life and career goals.

- Design: Assist students to devise concrete and achievable goals.

- Deliver: Support students to follow through on their action plans. As an educator, one should support the students when they stumble, believe in their abilities and assist them continuously to update and refine their goals/dreams.

- Do not settle: Challenge the students to proactively raise their internal bar of selfexpectations. 


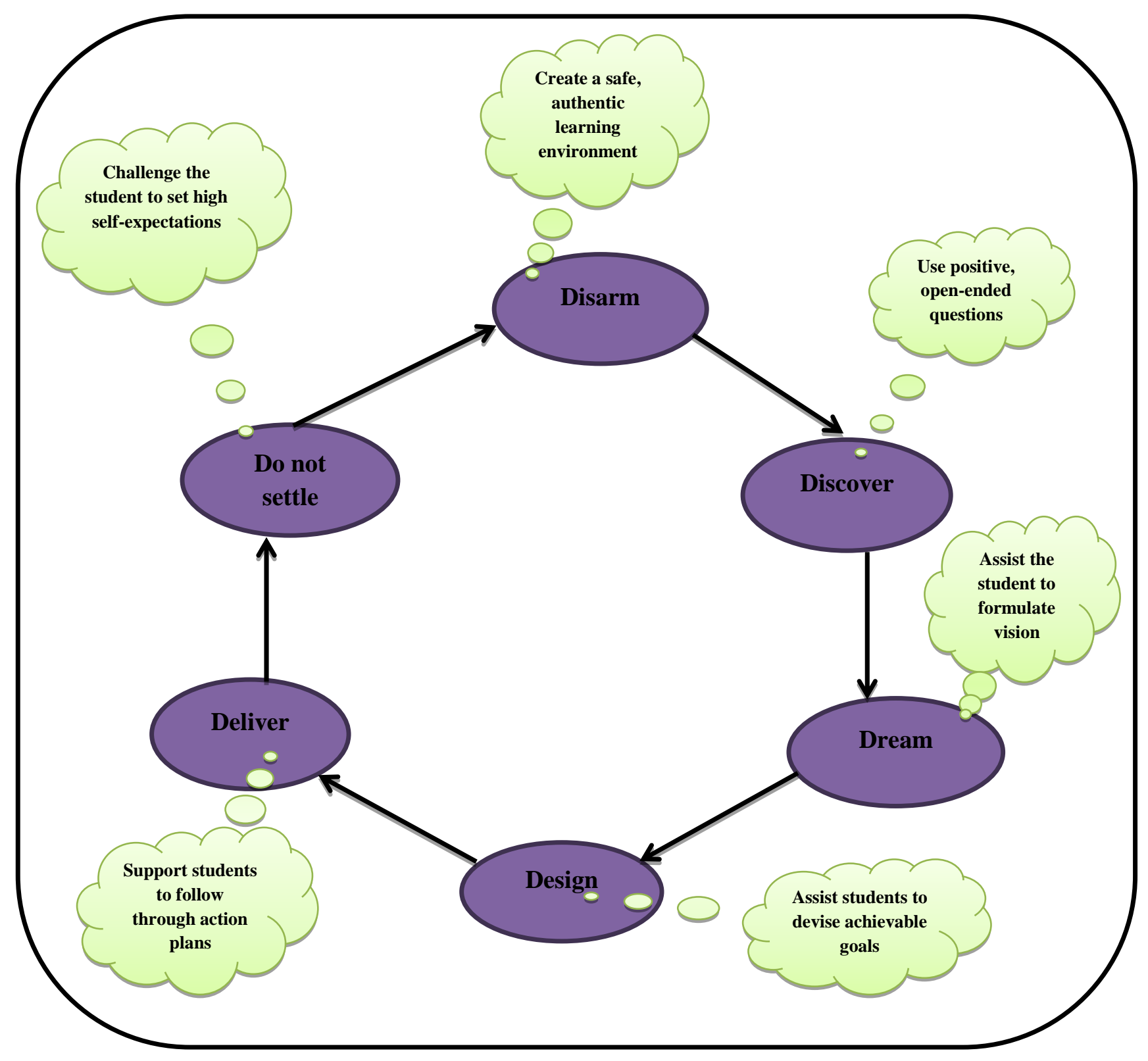

Figure 1: Six D Phase approach to educational practice (Bloom et al. 2013)

\section{Assessment: Appreciative educational practice}

Assessment should be structured in such a way that it is ongoing and provides an opportunity to make continual adjustments on the part of the educator and students as a means to achieve maximum performance. Earl_(2003) suggests the following three different approaches to assessment: assessment for learning (formative), assessment of learning (summative), and assessment as learning (selfreflection). All of these approaches should become part of the educators' everyday educational practice (Biggs, 2000). 
Assessment for learning should be done at all stages of a programme on a continuous basis, rather than at the end of the module/programme. Educators play the central role during the assessment, as the educator should utilise their personal knowledge of the student, their understanding of the context of the assessment and the learning outcomes to identify specific learning needs. Assessment for learning should be an interactive process with educators providing assistance as part of the assessment (Earl, 2003). Feedback is provided on a one-to-one or small group basis. The educators collect a wide range of data so that they can, if necessary, amend the learning for the students. The educator makes a judgement or grades a student's work by allocating a specific mark. The educator should keep a record of each student's progress against the set learning outcomes. Record-keeping in this approach might include, for example, using a checklist to monitor and evaluate marks obtained for assignments, tests, portfolios and/or clinical assessments that have been completed.

Assessment of learning summarises what the students have learned at the end of a specific aspect of a programme such as a study theme or module. Traditionally, it may take the form of a test and/or final examination. The questions are based on the content of the study theme or module, and the results are expressed as a symbol score; for example, $75 \%$. Feedback to students is provided to the entire group, focusing more on general achievements and/or challenges identified during the assessment and not so much on individual aspects for improvement. For example, the educator will focus the feedback on specific questions the class in general did not answer correctly, or which they misinterpreted.

Assessment as learning includes both self- and peer assessment and encourages students to take more responsibility for their own learning (Biggs, 2000; Andrade \& Du 2007). In the view of Earl (2003), the ultimate goal of assessment as learning is where students act as their own best assessors. Students as critical assessors should be actively engaged in self- and peer assessment. During the assessment as learning process, students make judgements of their own and their peers' learning. This process enables students to make sense of information related to prior knowledge, as well as mastering the skills involved, to work cooperatively and learn from critical appraisal received from peers. Furthermore, giving and receiving feedback develops students' interpersonal abilities and awareness of group dynamics, while also developing life-long evaluation skills about their own and others' work. Taking the first step towards self-directed and life-long learning, students are able to learn directly by critiquing their own and others' work, thereby becoming aware of their own learning style (Biggs 2000; Race 2000; Topping 2008; Nicol \& Draper 2008). Students are enabled to identify their own strengths and learning needs (Andrade \& Du 2007). The assessment as learning process occurs when students personally monitor what they are learning and use the feedback to judge the quality of their performance according to the set learning outcomes. They are then able to adjust or make changes to what they understand. An important aspect of assessment as learning is for students to 
continuously reflect on their work and make judgements on how they can make the most of what they have learned, thereby engaging in life-long learning activities (Boud \& Falchikov 2006).

Self and peer assessment

A balance between assessment for learning and assessment of learning is vital to ensure an integrative approach to assessment (O'Neill 2012). Students have to be provided with multiple assessment opportunities, constructive feedback and utmost exposure to learning to maximise their human potential and development, and to optimise their performance in an authentic learning environment where they can flourish. Assessment and feedback should be linked and integrated. Following assessment, the educator needs to provide the student with constructive feedback.

Here are some examples of how to use self- and peer assessment:

- Anonymously assess peers during a class presentation, using a rubric that was co-constructed by the educator, students and/or clinical facilitator (class, group or PowerPoint presentation).

- Peer assessment can be conducted as a small group activity such as discussing feedback among group members before giving feedback to peers.

- Commenting on a draft/final project of peers (verbal or written comments) based on the learning outcomes set for the task /and or a specific rubric.

- Discussing and suggesting improvements to others' (peers') work.

- Reflecting on improving your own work.

- Assessing your own work and proposing a final mark for an assignment.

\section{Feedback: Appreciative educational practice}

Feedback is information about how the students' present state of learning and performance relate to the set learning outcomes for the programme (Zimmerman \& Schunk 2001). Assessment and feedback can be used to empower students to become self-regulated learners. In educational practice, self-regulation is embedded in the active monitoring and evaluation of different learning processes; for example, learning outcomes, strategies used to achieve outcomes, the management of resources and external feedback (Pintrich \& Zisho 2002). Feedback should be given as soon as possible after the completion of a specific learning task so as to enhance learning. Feedback is regarded as a conversational process, and both the educator and students should participate. Having a conversation with the student in an environment conducive to feedback may enhance the student's receptivity to feedback, as power is shared between the assessor and the assessed (Nicol \& Draper 2008). Feedback should demonstrate appropriate ways of promoting performance in relation to the learning task and of 
the strategies that will enhance the learner's responsibilities, thus improving performance (Hattie \& Timperley 2007).

Effective feedback principles that can be used by educators and/or clinical facilitators suggested by Nicol and Draper (2008) and Kwong (2001) include:

- Design feedback comments that invite self-assessment and planning of future learning (individual, small group or class).

- Engage students in conversations relating to the purpose of the feedback.

- Clarify the goals, criteria and standards of expected performance.

- Deliver quality feedback information that helps learners to self-correct.

- Provide opportunities to act on feedback; for example, give an additional learning task.

- Encourage interaction and dialogue around learning (peer, student and educator).

- Facilitate the development of self-assessment and reflection.

- Involve students in decision-making about assessment practices (such as rubrics used for assessment).

- Support the development of cooperative learning groups (divide the class into cooperative learning groups and provide students opportunities to work in these groups).

- Provide appreciative feedback that influences students' motivation and self-esteem.

In the view of Hattie and Timperley (2007), the main purpose of feedback is to reduce the gap between current understanding, performance and the learning outcome. Three important questions should be asked when giving feedback:

- "What are the outcomes?"

- "What is the progress made towards the outcomes?"

- "What activities are to be undertaken to make better progress?"

In relation to these three questions, the answers will provide appropriate ways of enhancing performance of the learning task, and pose strategies that motivate the learner to take responsibility for learning so as to improve performance. It is very important that the educator offers opportunities for students to give feedback to each other; for example, following peer assessment. At this point, the educator should give feedback on the students' feedback given to peers to further enhance the learning process.

Hattie and Timperley (2007) are of the opinion that there are four levels of feedback: 
- The first level focuses on the learning task, indicating the creativeness of the work. This level of feedback should include directions to guide the student such as: "You need to include more about ..." or "You should also focus on ...".

- The second level of feedback should be aimed at the process followed to complete the learning task. This level of feedback is directed at the learning processes required to complete a learning task. For example: "You should focus on ensuring that the signs and symptoms are discussed in terms of the related pathophysiology ...".

- The third level of feedback should focus on the self-regulation level of the students, including greater skill in self-evaluation (assessment on learning). Students can be asked to reflect on the mark they should be given or on what they have learned whilst completing the learning task. This type of feedback influences the self-efficacy and self-belief of students, enhances internal motivation and self-regulation which, in turn, increases their general performance in the module/programme.

- The fourth level of feedback is personal and is directed at the student's self. Examples include: "You are a great student ..."; "Well done, that is an excellent question ...".

\title{
Conclusion
}

"The significant problems we face cannot be solved at the same level of thinking we were at when we created them."

\begin{abstract}
-Albert Einstein-
Appreciative education is driven by a shared commitment from educators towards students to encourage success and approach challenges as opportunities for growth. Educators using appreciative education, derived from Appreciative Inquiry, to guide everyday assessment and feedback practices can impact positively on student performance and the quality of products delivered by NEIs. Using appreciative language during assessment and feedback and applying the Six-D phases of appreciative education can enhance students' internal motivation, creativity and innovation. The attributes of appreciative education enable educators to design for and deliver competent nurse practitioners who will provide quality healthcare. Appreciative education is destined to realise the co-constructed destiny of the National Department of Health to deliver quality care to all citizens in South Africa.
\end{abstract}




\section{Reference list}

Andrade, H \& Du, Y. 2007. Students' responses to criteria-referenced self-assessment. Assessment and Evaluation in Higher Education 32 (2): 159-181.

Armstrong, S. 2008a. The concept of quality nursing education.

Biggs, J. 2000. Teaching for Quality Learning at University. Buckingham: Open University Press.

Bloom, J.L., Hutson, B.L., \& He, Y. and Konkle, E. 2013. Appreciative Education. Positive psychology and appreciative inquiry in higher education. Champaign, IL: Stipes Publishing. L.L.C

Boud, D. \& Falchikov, N. 2006. Aligning assessment with long-term learning. Assessment and Evaluation in Higher Education 31 (4): 399-413.

Coghlan, A.T., Preskill, H., \& Catsambas, T.T. 2003. An overview of appreciative inquiry in evaluation. New Directions for Evaluation 100: 5-22.

Earl, L. 2003. Assessment as Learning: Using Classroom Assessment to Maximise Student Learning. Thousand Oaks, CA: Corwin Press.

Erp, M.J. \& Lovrich, M. 2006. Overcome barriers to change in police organizations. [Online]. Available: http://eric.et.gov/ERICDocs/data/ericdocs2sql/content

Hattie, J., \& Timperley, H. 2007. The power of feedback. Review of Educational Research 77: 81112.

Havens, D.S., Woods, S.O., \& Leeman, J. 2006. Improving nursing practice and patient care. The Journal of Nursing Administration 36 (10): 463-470.

Kotzé, W. (ed.). 2008. Nurse Educators' Guide to Management. Pretoria: van Schaik.

Mohr, B.R., \& Watkins, J.M. 2002. The Essentials of Appreciative Inquiry: A Roadmap for Creating Positive Futures. Waltham: Pegasus Communications.

Moore, M. 2008. Appreciative Inquiry: The why? The what? The how? Practice Development in Health Care 7 (4): 214-220. 
Nicol, D., \& Draper, S. 2008. Redesigning written feedback to students when class sizes are large. Paper presented at the Improving University Teachers Conference: July, Glasgow.

O'Neill, G. 2012. The balance between assessment FOR and OF learning. UCD reaching and learning, Dublin.

Pintrich, P.R., \& Zisho, A. 2002. The development of academic self-regulation: The role of cognitive and motivation factors.

Preskill, H., \& Catsambas, T.T. 2006. Reframing evaluation through appreciative inquiry. London: Sage.

Race, P. 2001. The Lecturer's Toolkit. (2 ${ }^{\text {nd }}$ Ed.). London: Kogan Page.

Reed, J. 2007. Appreciative inquiry: Research for change. London: Thousand Oaks.

Republic of South Africa, National Department of Health. 2007. A policy on quality in health care for South Africa. Government Printers.

Stefaniak, K. 2007. Discovering nursing excellence through appreciative inquiry. Nurse Leader 5(2): $42-46$

Topping, K. 2008. Peer assessment. Theory into Practice 48 (1): 20-27.

Watkins, J.M., \& Cooperrider, D. 2008. Appreciative Inquiry: a transformative Paradigm. [Online]. Available: http://www.sd51.bc.ca/AI/AI\%20a\%20transformative\% paradigm.pdf .

Wigfield, A., \& Eccles, J.S. (eds). 2002. Students' Perceptions in the Classroom. San Diego, CA: Academic.

Zimmerman, B.J., \& Schunk, D.J. 2001. Self-regulated learning and academic achievement: Theoretical perspective. $2^{\text {nd }}$ ed. Mahawah,NJ: Lawrence Erlbaum Associates. 